\title{
Surgery after neoadjuvant immunotherapy in patients with resectable non-small cell lung cancer
}

\author{
Caroline Huynh ${ }^{1,2}$, Logan A. Walsh ${ }^{2,3}$, Jonathan D. Spicer ${ }^{1,2,4}$ \\ ${ }^{1}$ Research Institute of the McGill University Health Centre, Montreal, QC, Canada; ${ }^{2}$ Rosalind and Morris Goodman Cancer Research Centre, \\ McGill University, Montreal QC, Canada; ${ }^{3}$ Department of Human Genetics, McGill University, Montreal, QC, Canada; ${ }^{4}$ Division of Thoracic and \\ Upper Gastrointestinal Surgery, Department of Surgery, McGill University, Montreal, QC, Canada \\ Contributions: (I) Conception and design: All authors; (II) Administrative support: All authors; (III) Provision of study materials or patients: All \\ authors; (IV) Collection and assembly of data: All authors; (V) Data analysis and interpretation: All authors; (VI) Manuscript writing: All authors; (VII) \\ Final approval of manuscript: All authors. \\ Correspondence to: Jonathan D. Spicer, MD, PhD, FRCSC. Assistant Professor of Surgery, Division of Thoracic and Upper Gastrointestinal Surgery, \\ Department of Surgery, McGill University Health Centre, McGill University, 1650 Cedar Avenue, L8.520, Montreal, QC, H3G 1A4, Canada. \\ Email: jonathan.spicer@mcgill.ca.
}

\begin{abstract}
Surgery is the standard of care for patients with operable non-small cell lung cancer (NSCLC). However, as a single modality, surgery for early stage or locally advanced NSCLC remains associated with high rates of local and distant recurrence. The addition of neoadjuvant or adjuvant chemotherapy has modestly improved outcomes. While systemic therapy paired with surgery for other malignancies such as breast cancer have resulted in far better outcomes for equivalent stage designations, outcome improvements for operable NSCLC have lagged in part as a result of trials where adjuvant chemotherapy seemed to incur harm for stage IA patients and only modest survival benefit for stage IB-IIIA patients (AJCC $7^{\text {th }}$ ed.). In recent years, immunotherapy for NSCLC has emerged as a systemic therapy with significant benefit over traditional chemotherapy regimens. These advances with immune checkpoint inhibitors (ICIs) have opened the door to administering peri-operative immunotherapy for operable NSCLC. As a result, a great multitude of studies investigating the use of immunotherapy in combination with surgery for NSCLC as well as several other malignancies have emerged. In this review, we outline the rationale for neoadjuvant immunotherapy in the treatment of operable NSCLC and summarize the available evidence that include preoperative ICI as a single modality or in combination with systemic agents and/or radiotherapy. Further, we summarize how such treatment trajectories open multiple unique windows of opportunity for scientific discovery and potential therapeutic gains for these vulnerable patients.
\end{abstract}

Keywords: Immunotherapy; neoadjuvant therapy; carcinoma, non-small-cell lung; thoracic surgery

Submitted Mar 27, 2020. Accepted for publication Sep 01, 2020.

doi: $10.21037 /$ tlcr-20-509

View this article at: http://dx.doi.org/10.21037/tlcr-20-509

\section{Introduction}

Screening of high-risk individuals has demonstrated value in terms of improved survival from lung cancer by virtue of effecting a significant stage shift at the time of first diagnosis. As a result, patients who might have otherwise presented at an inoperable stage have been offered curative surgery (1-3). While implementation of lung cancer screening remains a challenge, the expected stage shift in coming years as a result of early detection have in part fuelled the desire to explore new paradigms of care for these patients. Due to the aggressive nature of lung cancer, overall and disease-specific outcomes after surgery for nonsmall cell lung cancer (NSCLC) have lagged behind other malignancies, even in the early stages of the disease $(2,4-6)$. In fact, even with successes and improvements in local 
therapies, local and distant recurrence rates remain high after surgery for NSCLC (7-9). Adjuvant therapies have been part of treatment standards to eliminate microscopic disease or residual disease and prevent recurrence (10). While novel adjuvant therapies have dramatically improved outcomes for operable patients with breast cancer and melanoma, the serach for improved adjuvants in NSCLC has been slow $(11,12)$. Chemotherapy has been the mainstay of therapy for advanced NSCLC since the 1990s $(13,14)$, leading to multiple trials in the neoadjuvant setting for early stage NSCLC (15). Chemotherapy, whether neoadjuvant or adjuvant, is estimated to provide an overall benefit on patients' 5 -year survival rate of only $\sim 5 \%$ higher than in the surgery only group, and such treatment courses are accompanied by their notable attendant adverse event rates (15-17). From the results of these initial trials, a significant debate emerged around the potential harm of chemotherapy in the neoadjuvant setting. The Albain et al. study compared chemoradiotherapy alone to chemoradiotherapy followed by surgery, and demonstrated a potential survival advantage with the addition of surgery in stage IIIA NSCLC as well as the potential harm of surgery after such a regimen if a pneumonectomy was required (18). As a result, the last two decades can be characterized largely by "up-front" surgery for early and locally advanced NSCLC followed by adjuvant chemotherapy (where indicated and if tolerated); versus pre-operative chemoradiotherapy for patients with stage IIIA NSCLC. Of note, multiple retrospective studies have recently shown that whether pre-operative chemotherapy or chemoradiotherapy is employed, outcomes are largely the same, indicating that conventional therapies have plateaued for locally advanced NSCLC (19-22). Another excellent study by Brandt et al. at Memorial Sloan Kettering Cancer Center has since shown that while oncological outcomes are essentially the same if chemotherapy is administered before or after surgery, adverse events from systemic therapy occur far more in the adjuvant setting than in the neoadjuvant setting (23). Indeed, such findings point to the importance of tracking adverse events through the totality of the treatment course and placing emphasis on the patient experience of therapy when oncological outcomes trend towards the same endpoint. Fortunately, the advent of immunotherapy has opened a new era in lung cancer care. Even as a single agent, an immune checkpoint inhibitor (ICI) provides significant benefit over chemotherapy for stage IV NSCLC (24). These benefits include better side effect profiles, improved disease-specific outcomes, and prolonged survival; the result of which ICI is now first-line therapy in advanced NSCLC (25). The encouraging outcomes of immunotherapy in metastatic NSCLC repositioned neoadjuvant treatment as a potential option that may minimize harm and provide several significant gains.

\section{Immunotherapy for locally advanced and metastatic NSCLC}

In the setting of advanced, metastatic NSCLC, several randomized phase III trials led to the approval of nivolumab (anti-PD-1), pembrolizumab (anti-PD-1) and atezolizumab (anti-PD-L1) as monotherapies (26-30). PD-L1 tumor surface expression was suggested to be predictive of response and survival (31-33). Several trials also revealed that the addition of ICIs to standard chemotherapy compared to chemotherapy alone was safe, and also resulted in prolonged progression-free survival (PFS) and overall survival (OS) (34-38). In patients with driver mutations (e.g., $E G F R, A L K$ ), ICIs led to an inferior OS when compared to docetaxel (39). The use of ICI in EGFR and $A L K$ mutant NSCLC patients has been controversial and trials have mostly excluded these patients to focus on those for whom targeted therapies are not otherwise available (34-38). Another topic of interest in advanced NSCLC is the combination of an anti-PD-1 or anti-PD-L1 to an anti-CTLA-4. Results have shown improved response and survival with ICI or combination chemotherapyICI compared to chemotherapy alone (40-42). Yet, these advances are only a small step in the right direction as most patients continue to die within 2 to 3 years of diagnosis (42). As a result, strategies to optimally treat early stage disease and avoid progression to metastasis is of utmost importance, and research focused on the efficacy of systemic therapies in early stages of NSCLC may accelerate developments for patients with metastatic disease.

For inoperable stage III NSCLC, concurrent or sequential chemoradiation is the perennial standard of care (43), but recurrence rates are high, and survival is poor (44). Durvalumab (anti-PD-L1), as consolidation therapy for patients without progression after chemoradiation, demonstrated safety, and significantly improved PFS and OS as compared to placebo (45-47). For patients for whom surgery was the primary modality of local control, several phase III clinical trials are ongoing (48-50), but the very nature of adjuvant trials significantly prolongs the interval towards conclusive results (Table 1) (51). Results from PACIFIC have been dramatic, and opened the question as to whether operable stage III patients may in fact benefit 
more from concurrent chemoradiation followed by ICI rather than to proceed with surgical resection. The next wave of studies employing immunotherapy on the backbone of concurrent chemoradiation are forthcoming (52-55). These studies will set the stage to address larger questions about the place of surgery in locally advanced disease.

Additional monoclonal antibodies acting through a different pathway than the PD-1/PD-L1 and CTLA-4 axes have also been considered. Based on an initial study showing that Canakinumab was associated with a dosedependent reduction in incidence and mortality from lung cancer $(56,57)$, recent randomized prospective studies have considered it as a potential treatment option for NSCLC as a single agent or in combination with ICI or chemotherapy (58-61). This agent has a high affinity for interleukin-1-beta (IL1B) which promotes angiogenesis, tumor invasion and induced immunosuppression. While pre-clinical evidence for efficacy of IL1B inhibition in cancer is sparse, the product sponsor has employed it in the peri-adjuvant space as an effort to confirm or disprove its biological efficacy for NSCLC patients.

\section{Neoadjuvant immunotherapy for operable NSCLC}

The success of immunotherapy in the neoadjuvant setting for several cancer types (24), such as breast cancer (62), melanoma (63-68) and urological cancer (69), combined with the overwhelming successes of ICI as an adjuvant to chemoradiation for stage III NSCLC, contribute to a strong rationale for pursuing neoadjuvant studies in lung cancer. Numerous parallels can be drawn in the evolution of oncology care in these disease sites such as how preoperative therapy could allow for greater preservation of lung parenchyma and function similar to how the surgical management of breast cancer over the last century has evolved allowing for breast conserving surgery to become the standard thanks to effective systemic therapy $(70,71)$.

Surgery is still recognized as a cornerstone for cure in NSCLC. Moreover, when complete resection is feasible, surgery remains the ultimate form of local disease control. As such, surgeons and oncologists alike have long felt a sense of urgency to proceed to surgery when a patient presents with operable disease. However, as far back as the early 1990s, it was recognized that pre-operative chemotherapy can dramatically improve survival for patients with stage III NSCLC (72-74). In fact, in one of the first reports exploring peri-operative chemotherapy for stage III NSCLC, Roth et al. had to abort their study at interim analysis due to the extreme benefit of peri-operative chemotherapy in their randomized trial design (72). Shockingly, as recently as 2016 , US data indicate that only $5 \%$ of patients will be offered pre-operative systemic therapy, with the majority either receiving adjuvant treatment or nothing at all. This phenomenon highlights physicians' fears around the notion of missing a window of opportunity for surgery if systemic therapy is given beforehand or that the disease may progress to an inoperable stage whilst on systemic therapy. It also highlights the distaste that patients harbor for pursuing adjuvant chemotherapy after surgical resection. Such fears are understandable; however, even with chemotherapeutic regimens from the late $80 \mathrm{~s}$ and early $90 \mathrm{~s}$, progression on treatment occurred in only $15 \%$ of patients. Arguably, patients who progress on systemic therapy are unlikely to benefit from the potential local control offered by surgery and may in fact be significantly harmed by its inherent morbidity. Our team is certainly of the opinion that little is lost and in fact much is to be gained from pre-operative therapy for patients with operable NSCLC. The data presented below hopefully offer an even stronger argument in the era of immunotherapy, while still recognizing some of the limitations to the approach.

Despite complete resections, progression leading to death occurs far too frequently (75). A systematic review and meta-analysis of stage II to IIIB patients demonstrated similar oncological benefit with neoadjuvant chemotherapy compared to surgery, including a $13 \%$ reduction in relative risk of death as well as an improved recurrence-free survival (RFS) and OS for resectable NSCLC (15). Importantly, adjuvant chemotherapy is widely accepted for this patient population, though survival benefits are modest and many patients are unfit for treatment after suffering the impacts of surgery $(16,17)$. In fact, results from a study by Brandt et al. comparing outcomes after neoadjuvant or adjuvant chemotherapy in NSCLC revealed that neoadjuvant chemotherapy led to fewer grade 3 or greater toxicities and to a higher likelihood of receiving full doses and cycles of chemotherapy, suggesting a potential advantage of neoadjuvant over adjuvant therapy (23).

Although adjuvant chemotherapy has been considered the standard of care for many years, recent results from ADAURA, a phase III double-blind randomized trial evaluating the efficacy and safety of osimertinib (tyrosine kinase inhibitor) compared to placebo in EGFR-positive stage IB-IIIA NSCLC following complete tumor resection with or without adjuvant chemotherapy, have suggested 
Table 1 Select adjuvant immunotherapy trials for the treatment of resected NSCLC

\begin{tabular}{|c|c|c|c|c|c|c|}
\hline $\begin{array}{l}\text { Trial identifier (estimated } \\
\text { primary completion) }\end{array}$ & Study name and sponsor & Phase & Intervention & $\begin{array}{l}\text { Estimated } \\
\text { enrollment }\end{array}$ & Stage & $\begin{array}{l}\text { Primary } \\
\text { endpoints }\end{array}$ \\
\hline $\begin{array}{l}\text { NCT02486718 (Nov. } \\
\text { 2020) }\end{array}$ & $\begin{array}{c}\text { IMpower010, Hoffman-La } \\
\text { Roche (USA) }\end{array}$ & III & $\begin{array}{l}\text { Atezolizumab vs. best } \\
\text { supportive care }\end{array}$ & 1,280 & IB-IIIA (v7) & DFS \\
\hline $\begin{array}{l}\text { NCT02504372 (Aug. } \\
\text { 2021) }\end{array}$ & $\begin{array}{c}\text { KEYNOTE-091/PEARLS, } \\
\text { Merck (USA) }\end{array}$ & III & $\begin{array}{l}\text { Pembrolizumab vs. } \\
\text { placebo }\end{array}$ & 1,080 & IB-IIIA (v7) & DFS \\
\hline NCT02595944 (Jul. 2024) & ANVIL, NCI (USA) & III & Nivolumab vs. observation & 903 & IB-IIIA (v7) & DFS, OS \\
\hline
\end{tabular}

NSCLC, non-small cell lung cancer; DFS, disease-free survival; NCl, National Cancer Institute; OS, overall survival.

a strong benefit for adjuvant targeted therapy as well in EGFR-positive NSCLC (76). In fact, an interim analysis of 683 patients revealed that osimertinib was safe and led to a significantly higher 2-year disease-free survival (DFS) after surgery and adjuvant chemotherapy (76).

Following the successes with anti-PD-1/anti-PD-L1 immunotherapy in improving survival for advanced and metastatic NSCLC patients, a recent prospective phase II pilot trial by Forde et al., using two preoperative doses of nivolumab in stage I to IIIA, evaluated the safety and feasibility of neoadjuvant immunotherapy in resectable NSCLC tumors. Twenty-one patients were enrolled, 20 of which underwent complete resection of their lung cancer. Neoadjuvant nivolumab was well-tolerated, associated with few side effects, did not delay time to surgery and led to $45 \%$ major pathological response (MPR) in resected tumors, including $15 \%$ pathological complete response (pCR) and $40 \%$ pathological downstaging. Side effects included $23 \%$ treatment-related adverse events of any grade (fever, gastrointestinal effects, infusion reaction, delirium and dry skin), and one case of a grade 3 adverse event which was a pneumonia requiring an uncomplicated surgery. Although this study had a small number of patients and a short follow-up period, it was the first study to show the safety of neoadjuvant immunotherapy (77). Additionally, MPR occurred in both high and low PD-L1 status (77), which is different from previously published results with metastatic NSCLC (33). Pre-treatment tumor mutational burden (TMB) was not predictive of pathological response to anti-PD-1 therapy though many patients had insufficient pre-treatment tissue to assess TMB (77). In comparison, previous neoadjuvant chemotherapy trials for operable NSCLC reported pCR rates between $0 \%$ and $16 \%$ (median: $4 \%)(51,72,74,78-82)$ and MPR rates between $20-25 \%$

\section{$(51,83,84)$.}

Several other published phase II studies evaluated the use of anti-PD-1, anti-PD-L1 and anti-CTLA-4 monotherapy or combination immunotherapy as neoadjuvant treatment for resectable NSCLC (Table 2 and Figure 1). The NEOSTAR trial evaluated nivolumab versus combination nivolumab/ipilimumab for stages I-IIIA(N2), demonstrating an appropriate safety profile with a $29 \%$ MPR rate for combination therapy compared to $17 \%$ for monotherapy, and $19 \%$ compared to $9 \%$ pCR rate, respectively. Surgical complications included two bronchopleural fistulas (nivolumab arm) and eight air leaks (five in the nivolumab arm, three in the nivolumab-ipilimumab arm). Treatmentrelated adverse events included one death due to a bronchopleural fistula post-steroid-treated pneumonitis (nivolumab arm), and four grade 3 adverse events including pneumonia, hypoxia, hypermagnesemia (nivolumab arm) and diarrhea (nivolumab-ipilimumab arm). At the time of analysis, 44 patients were randomized, but 10 patients did not undergo surgery after immunotherapy treatment $(23 \%)$. It is unclear why the rate of unresected patients was so high, but this data point remains rather concerning and worthy of close monitoring. Another interesting finding was the induction of higher $T$ cell proliferation and activation compared to untreated tumors, and the association of both radiological and pathologic anti-tumor activity with higher pre-treatment PD-L1 levels. In the near future, the NEOSTAR study will also be comparing nivolumab with chemotherapy to nivolumab only (85). The LCMC3 trial, which studied atezolizumab for operable stages IBIIIB NSCLC, reported interim results with 90 patients having completed the protocol. Due to previous evidence indicating a lower efficacy of immunotherapy in patients with EGFR or ALK mutated NSCLC (39), eight patients 
Table 2 Select neoadjuvant immunotherapy trials for the treatment of operable NSCLC

\begin{tabular}{|c|c|c|c|c|c|c|}
\hline $\begin{array}{l}\text { Trial identifier (estimated } \\
\text { primary completion) }\end{array}$ & $\begin{array}{l}\text { Study name and } \\
\text { sponsor }\end{array}$ & Phase & Intervention & $\begin{array}{l}\text { Estimated } \\
\text { enrollment }\end{array}$ & Stage & $\begin{array}{l}\text { Primary } \\
\text { endpoints }\end{array}$ \\
\hline \multicolumn{7}{|c|}{ Immunotherapy monotherapy } \\
\hline $\begin{array}{l}\text { NCT02818920 (Mar. } \\
\text { 2019) }\end{array}$ & $\begin{array}{l}\text { TOP1501, Duke } \\
\text { University (USA) }\end{array}$ & ॥ & Pembrolizumab (single arm) & 32 & IB-IIIA & $\begin{array}{c}\text { Surgical } \\
\text { feasibility rate }\end{array}$ \\
\hline $\begin{array}{l}\text { NCT03197467 (Feb. } \\
\text { 2020) }\end{array}$ & $\begin{array}{l}\text { NEOMUN, AIO-Studien- } \\
\text { gGmbH (Germany) }\end{array}$ & II & Pembrolizumab (single arm) & 30 & $\|-\| I A$ & $\begin{array}{l}\text { Safety, clinical } \\
\text { and pathological } \\
\text { responses }\end{array}$ \\
\hline $\begin{array}{l}\text { NCT02927301 (Feb. } \\
\text { 2020) }\end{array}$ & $\begin{array}{l}\text { LCMC3, Genentech } \\
\text { Inc. (USA) }\end{array}$ & II & Atezolizumab (single arm) & 180 & IB-IIIB & MPR \\
\hline \multicolumn{7}{|c|}{ Combination immunotherapies } \\
\hline $\begin{array}{l}\text { NCT03794544 (Mar. } \\
\text { 2022) }\end{array}$ & $\begin{array}{l}\text { NeoCOAST, Medlmmune } \\
\text { LLC (USA) }\end{array}$ & II & $\begin{array}{l}\text { Durvalumab vs. durvalumab } \\
\text { + oleclumab or monalizumab } \\
\text { or danvatirsen (four arms) }\end{array}$ & 160 & I-IIIA & MPR \\
\hline $\begin{array}{l}\text { NCT02259621 (Jan. } \\
\text { 2023) }\end{array}$ & SKCCC at JH (USA) & II & $\begin{array}{c}\text { Nivolumab vs. nivolumab + } \\
\text { ipilimumab }\end{array}$ & 30 & $\begin{array}{l}\text { High risk } \\
\text { IB-IIIA }\end{array}$ & Safety \\
\hline \multicolumn{7}{|c|}{ Combination immunotherapy and chemotherapy } \\
\hline $\begin{array}{l}\text { NCT02716038 (Apr. } \\
\text { 2020) }\end{array}$ & Columbia University (USA) & II & $\begin{array}{c}\text { Atezolizumab + } \\
\text { chemotherapy (single arm) }\end{array}$ & 30 & IB-IIIA & MPR \\
\hline $\begin{array}{l}\text { NCT02998528 (Apr. } \\
\text { 2020) }\end{array}$ & $\begin{array}{l}\text { CheckMate 816, } \\
\text { BMS (USA) }\end{array}$ & III & $\begin{array}{l}\text { Nivolumab + ipilimumab vs. } \\
\text { nivolumab + chemotherapy } \\
\text { vs. chemotherapy alone }\end{array}$ & 350 & IB-IIIA & EFS, pCR \\
\hline $\begin{array}{l}\text { NCT03081689 (Jun. } \\
\text { 2021) }\end{array}$ & $\begin{array}{l}\text { NADIM, Spanish Lung } \\
\text { Cancer Group (Spain) }\end{array}$ & II & $\begin{array}{l}\text { Nivolumab + chemotherapy } \\
\text { (single-arm) }\end{array}$ & 46 & IIIA (N2) & PFS \\
\hline $\begin{array}{l}\text { NCT03158129 (Jul. } \\
\text { 2021) }\end{array}$ & $\begin{array}{l}\text { NEOSTAR, } \\
\text { MDACC (USA) }\end{array}$ & II & $\begin{array}{c}\text { Nivolumab vs. nivolumab + } \\
\text { ipilimumab vs. nivolumab }+ \\
\text { chemotherapy }\end{array}$ & 66 & I-IIIA & MPR \\
\hline $\begin{array}{l}\text { NCT03366766 (Jul. } \\
\text { 2021) }\end{array}$ & SKCCC at JH (USA) & II & $\begin{array}{l}\text { Nivolumab + histology- } \\
\text { specific chemotherapy }\end{array}$ & 34 & I-IIIA & MPR \\
\hline $\begin{array}{l}\text { NCT03838159 (Mar. } \\
\text { 2022) }\end{array}$ & $\begin{array}{l}\text { NADIM II, Fundación } \\
\text { GECP (Spain) }\end{array}$ & II & $\begin{array}{c}\text { Nivolumab + chemotherapy } \\
\text { vs. chemotherapy }\end{array}$ & 90 & $\begin{array}{c}\text { IIIA-IIIB } \\
\text { (T3N2) }\end{array}$ & $\mathrm{pCR}$ \\
\hline $\begin{array}{l}\text { NCT03425643 (Jan. } \\
\text { 2024) }\end{array}$ & $\begin{array}{c}\text { KEYNOTE-671, Merck } \\
\text { (USA) }\end{array}$ & III & $\begin{array}{c}\text { Pembrolizumab + } \\
\text { chemotherapy vs. placebo }+ \\
\text { chemotherapy }\end{array}$ & 786 & II-IIIB (N2) & EFS, OS \\
\hline $\begin{array}{l}\text { NCT03456063 (Mar. } \\
\text { 2025) }\end{array}$ & $\begin{array}{l}\text { IMpower030, Hoffmann- } \\
\text { La Roche (USA) }\end{array}$ & III & $\begin{array}{l}\text { Atezolizumab + } \\
\text { chemotherapy vs. placebo + } \\
\text { chemotherapy }\end{array}$ & 374 & II-IIIB (T3N2) & EFS, MPR \\
\hline
\end{tabular}

Table 2 (continued) 
Table 2 (continued)

\begin{tabular}{|c|c|c|c|c|c|c|}
\hline $\begin{array}{l}\text { Trial identifier (estimated } \\
\text { primary completion) }\end{array}$ & Study name and sponsor & Phase & Intervention & $\begin{array}{l}\text { Estimated } \\
\text { enrollment }\end{array}$ & Stage & $\begin{array}{l}\text { Primary } \\
\text { endpoints }\end{array}$ \\
\hline \multicolumn{7}{|c|}{ Combination immunotherapy and radiotherapy } \\
\hline $\begin{array}{l}\text { NCT03217071 (Sep. } \\
\text { 2020) }\end{array}$ & PembroX, UCSF (USA) & II & $\begin{array}{c}\text { Pembrolizumab vs. } \\
\text { pembrolizumab + } \\
\text { radiation (SRT) }\end{array}$ & 40 & I-IIIA & $\begin{array}{c}\text { Change in number } \\
\text { of infiltrating } \\
\text { CD3+ T cells }\end{array}$ \\
\hline $\begin{array}{l}\text { NCT03237377 (Sep. } \\
\text { 2021) }\end{array}$ & SKCCC at JH (USA) & II & $\begin{array}{l}\text { Durvalumab + radiation } \\
\text { vs. durvalumab + } \\
\text { tremelimab + radiation }\end{array}$ & 32 & III & $\begin{array}{l}\text { Safety and } \\
\text { feasibility }\end{array}$ \\
\hline
\end{tabular}

NSCLC, non-small cell lung cancer; BMS, Bristol-Myers Squibb; DFS, disease-free survival; EFS, event-free survival; JH, Johns Hopkins; MDACC, MD Anderson Cancer Centre; MPR, major pathological response; OS, overall survival; pCR, pathological complete response; PFS, progression-free survival; SKCCC, Sidney Kimmel Comprehensive Cancer Center at Johns Hopkins; IFCT, Intergroupe Francophone de Cancérologie Thoracique; SBRT, stereotactic body radiation therapy; UCSF, University of California at San Francisco.

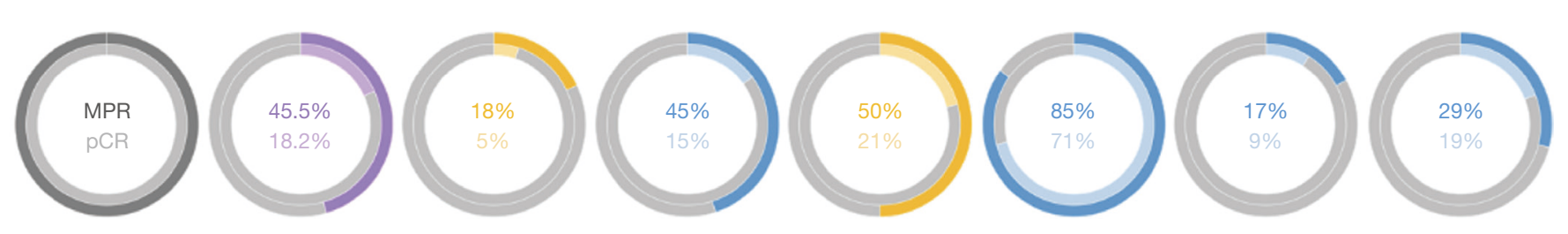

\begin{tabular}{|c|c|c|c|c|c|c|c|}
\hline & $\begin{array}{c}\text { National Cancer } \\
\text { Center China }\end{array}$ & LCMC3 & Forde (SKCCC) & Shu (Columbia U.) & NADIM & $\begin{array}{l}\text { NEOSTAR } \\
\text { (Arm A) }\end{array}$ & $\begin{array}{l}\text { NEOSTAR } \\
\text { (Arm B) }\end{array}$ \\
\hline Treatment (cycles) & Sintilimab $\times 2$ & Atezolizumab $\times 2$ & Nivolumab ×2 & $\begin{array}{l}\text { Atezolizumab } \times 4 \text { plus } \\
\text { paclitaxel/carboplatin }\end{array}$ & $\begin{array}{c}\text { Nivolumab } \times 3 \text { plus } \\
\text { paclitaxel/carboplatin }\end{array}$ & Nivolumab $\times 3$ & $\begin{array}{c}\text { Nivolumab } \times 3 \\
\text { and ipilimumab } \times 1\end{array}$ \\
\hline Stage & IB-IIIA & IB-IIIB & I-IIIA & IB-IIIA & IIIA (N2) & & |-IIIA \\
\hline
\end{tabular}

Legend: SKCCC (Sidney Kimmel Comprehensive Cancer Center)

References: Li et al. (J Clin Oncol 2019), Rusch et al. (J Clin Oncol 2018), Kwiatkowski et al. (J Clin Oncol 2019), Forde et al. (N Engl J Med 2018), Shu et al. (J Clin Oncol 2018), Provencio-Pulla et al. (J Clin Oncol 2018), Provencio-Pulla et al. (J Clin Oncol 2019), Cascone et al. (J Clin Oncol 2019)

Figure 1 Heterogeneity of pathological responses in published neoadjuvant trials for NSCLC (77,85-91). Various pCR and MPR rates were published in recent neoadjuvant immunotherapy trials for operable NSCLC. The effect of the molecule itself and the technique used for response assessment are two important factors that could explain this phenomenon. NSCLC, non-small cell lung cancer; MPR, major pathological response; pCR, complete pathological response.

in LCMC3 were excluded from the analysis. While such exclusion may be tempting, mutational testing limitations in early stage disease are a reality that requires careful attention moving forward. Nonetheless, the study showed an overall $18 \%$ MPR rate, including $5 \%$ pCR. PD-L1 positive patients had higher rates of MPR, especially if the tumor proportion score was over 50\%. Atezolizumab was also found to be safe and well-tolerated; two treatmentunrelated deaths (cardiac-related death post-surgical resection and death due to disease progression) and $6 \%$ treatment-related grade 3 and 4 adverse events (86,87). A phase IB open-label trial studying the efficacy and safety of sintilimab (anti-PD-1) for resectable stages IB to IIIA squamous NSCLC in China achieved an MPR of $45.5 \%$ including $18.2 \%$ pCR. Additionally, a decrease in positronemission tomography and computed tomography (PET-CT) standard uptake values (SUVs) was found to be predictive of pathological response (88). The NADIM trial was a phase II combination neoadjuvant chemotherapy with nivolumab followed by 1 year of adjuvant nivolumab for stage IIIA (N2 
disease or T4N0) NSCLC, for which recently published final results (46 enrolled patients, 41 surgeries performed) showed an $86 \%$ MPR and an unprecedented $71 \%$ pCR with downstaging seen in $93 \%$ of cases. Combination chetomtherapy-nivolumab was a well-tolerated neoadjuvant therapy: no surgery were delayed and none of the patients withdrew due to progression or toxicity. The NADIM trial was the first clinical study to explore combination of chemotherapy and immunotherapy in early stage NSCLC $(89,90)$. The NADIM II trial will be a phase II randomized trial comparing neoadjuvant chemo-immunotherapy versus chemotherapy alone for locally advanced NSCLC (NCT03838159). A phase II trial using combination neoadjuvant atezolizumab and chemotherapy (carboplatin and paclitaxel) followed by surgery (single arm) for stage IB to IIIA tumors recently presented early results which showed $50 \%$ MPR, including $21 \%$ pCR. MPR occurred in both PD-L1 positive or negative patients (91).

Considerable data in recent years has shown the efficacy of combined radiotherapy and immunotherapy compared to monotherapy. Preclinical studies show that PD-L1 expression can be upregulated on tumor cells after radiotherapy and that PD-L1 can enhance the cytotoxic effect of radiation, leading to a synergistic anti-tumor activity between radiation effects and PDL1 inhibition $(92,93)$. This finding led to a few phase II clinical trials on the addition of ICI to radiation therapy. The KEYNOTE-001 solid tumors' trial revealed that previous treatment with radiotherapy in patients with advanced NSCLC resulted in longer PFS and OS with immunotherapy than in patients who did not receive radiotherapy treatments (94). Another study is evaluating the efficacy of durvalumab combined to ablative stereotactive radiotherapy compared to durvalumab alone. Its preliminary results established a well-tolerated treatment with durvalumab, and an MPR of $47 \%$ in the combined arm compared to $0 \%$ with neoadjuvant ICI alone (95). Many tumors are considered to have a non-immunogenic or "cold" microenvironment for which immunotherapies may not work, but the effects could be synergistically enhanced by the use of chemotherapy, radiation or other combination therapies (96). It remains to be determined if neoadjuvant radio-immunotherapy creates intra- and post-operative challenges for these patients and whether surgical resection in this context has added value.

Although quite promising and encouraging, the results of these published trials still show a significant heterogeneity in clinical and pathological responses (see Figure 1). The effect of the molecule itself (anti-PD-1 vs. anti-PD-L1 $v s$. anti-CTLA-4), the dosing strategy and frequency of treatments, as well as the technique used for response assessment are all important factors that may contribute to this phenomenon. In fact, although many studies have used the model established by Hellmann et al. with systematic sampling of serial tumor sections with averaging to describe MPR (51), there is no internationally accepted protocol at this time in regards to pathological assessments. This emphasizes the need for a standardized practice combining available modalities to evaluate response to treatment, specifically to immunotherapy, given the complex biology of this modality and lack of long-term experience.

\section{Ongoing trials of neoadjuvant immunotherapy in lung and other cancers}

Despite the uplifting results of published phase II trials, the heterogeneity of these justify the establishment of largersized phase II and III trials testing safety and efficacy of various ICIs, either as single modalities or in combination with chemotherapy or radiotherapy.

A few single-arm phase II studies (PRINCEPS NCT02294576, NEOMUN and IoNESCO) are evaluating the safety and feasibility of monotherapy atezolizumab, pembrolizumab and durvalumab in resectable NSCLC. Results are pending $(97,98)$. The NeoCOAST trial (phase II) is studying durvalumab monotherapy compared to its combination with novel agents acting on the immune system meant to synergize with ICI (99). Moreover, larger randomized phase III trials are evaluating response and survival rates for combined immunotherapy and chemotherapy compared to chemotherapy alone. CheckMate 816 is assessing nivolumab and ipilimumab compared to nivolumab only with chemotherapy or chemotherapy alone for stages IB-IIIA NSCLC. This study plans to enroll 624 patients with MPR as the primary endpoint $(100,101)$. IMpower030 is evaluating the survival and pathological response of atezolizumab or placebo in combination with chemotherapy, planning to enroll 374 patients (102). An ongoing phase II single-arm trial is trialing neoadjuvant combination durvalumab with chemotherapy for the treatment of stage IIIA(N2) NSCLC, for which results, including event-free survival (EFS), are pending (103). Furthermore, AEGEAN is a phase III randomized trial also studying the addition of durvalumab to chemotherapy, but comparing it to chemotherapy alone. With a plan of enrolling 300 patients, the primary 
endpoint is MPR (104). Based on the CheckMate 012 trial, which showed a greater radiologic objective response of combination immunotherapy (nivolumab and ipilimumab) compared to monotherapy (nivolumab alone) (105), KEYNOTE-671 is an ongoing phase III randomized trial using pembrolizumab with platinum-based chemotherapy compared to placebo with chemotherapy for stages IIB to IIIA NSCLC, planning to enroll 786 patients (106). Finally, in the neoadjuvant setting, the PembroX study (NCT03217071) is comparing a combination of pembrolizumab and radiation therapy to pembrolizumab only for the treatment of resectable NSCLC. Another pilot study is also looking at neoadjuvant immunoradiation with durvalumab and tremelimumab in resectable stage IIIA NSCLC (NCT03237377). The safety and efficacy data resulting from these various studies could significantly add to practice-changing guidelines. Details regarding these ongoing trials can be found in Table 2 .

\section{Why neoadjuvant immunotherapy?}

In favor of neoadjuvant immunotherapy, there exists a body of preclinical data describing an increased efficacy as compared to adjuvant treatment (107-109). One central hypothesis is focused on leveraging the macroscopic tumor as a substrate for the development of cytotoxic T-cell clones with T-cell receptors that are specific to the patient's tumor neoantigens. Such T-cell clonotypes could be sustained over time and provide durable control of disease (109-111). It clearly remains to be determined if the presence of macroscopic tumor is required to achieve this or if adjuvant strategies can achieve a similar effect despite the pre-clinical data to the contrary. Interestingly, a preclinical model demonstrated that neoadjuvant immunotherapy (anti-PD-1) led to more elevated and sustained tumor-specific CD8+ T-cell responses which persisted beyond surgery, a greater overall therapeutic effect and improved survival $(40 \% v s$. $0 \%$ ) compared to adjuvant therapy in a model of metastatic triple-negative breast cancer. Various combinations of ICIs were in fact tested in both neoadjuvant and adjuvant contexts, and independent of types of immunotherapy used, neoadjuvant treatment was found to be superior to adjuvant treatment in treating micrometastases and leading to higher rates of cure in these mice. Neoadjuvant chemotherapy (paclitaxel) was also explored and did not yield significant benefit over adjuvant chemotherapy (107). Another preclinical mouse model study of pancreatic ductal adenocarcinoma compared the effects of adding a neoadjuvant or an adjuvant anti-PD-1 to standard chemotherapy treatment. Results showed that neoadjuvant was superior to adjuvant immunotherapy in enhancing chemotherapy's effect to eradicate tumor recurrence and leading to longer survival through increased $\mathrm{T}$ cell activation (108). In early stage NSCLC, a murine study revealed that a large proportion of tumor-infiltrating T-cells expressed PD-1 and that tumor tissues had higher PD-L1 expression than normal lung tissue. Also, its results showed that anti-PD-1 treatment controlled tumor growth, led to improved survival and reprogrammed tumor-associated lymphoid and myeloid cells. This study's results therefore suggest that the PD-1/PD-L1 axis is activated early in NSCLC (112).

In the Forde et al. study, mutation-associated, neoantigenspecific T-cell clones from the primary tumor were found to expand to the peripheral blood at 2 and 4 weeks after treatment (77). This is consistent with previous results in advanced NSCLC which observed significant responses in tumors with higher mutation-associated neoantigen load. This phenomenon was explained by clonal $\mathrm{T}$ cell expansion generating functional immune responses and therefore leading to increased durable responses. On the other hand, acquired resistance to immunotherapy would be associated with a loss of mutations encoding for tumor-specific neoantigens (through the elimination of tumor sub-clones and the chromosomal loss of truncal alterations) and with changes in $\mathrm{T}$ cell receptor clonality. This would explain the idea that response and resistance to immunotherapies can be comparable and similar within the same tumor types (113). A recent trial for resectable NSCLC also suggested that higher intratumoral T-cell receptor clonality was associated with decreased residual tumor at surgery and a higher MPR. This study further suggested that the exchange of T-cell clones between the tumor and the peripheral blood could represent a key correlate of pathologic response for neoadjuvant immunotherapy (114). Another study also suggested that $\mathrm{T}$-cell responses appear to persist in the peripheral blood years after treatment initiation (115), adding to the argument for the efficacy of neoantigen immunization as a result of neoadjuvant immunotherapy.

One of the major benefits of the neoadjuvant therapy design as a platform for scientific discovery is the expeditious nature of the experiment, providing results on biological efficacy within a short period of time. With advances in immuno-oncology bringing more tolerable treatments carrying fewer side-effects, neoadjuvant therapy trials could help bring more rapid advancements to the 


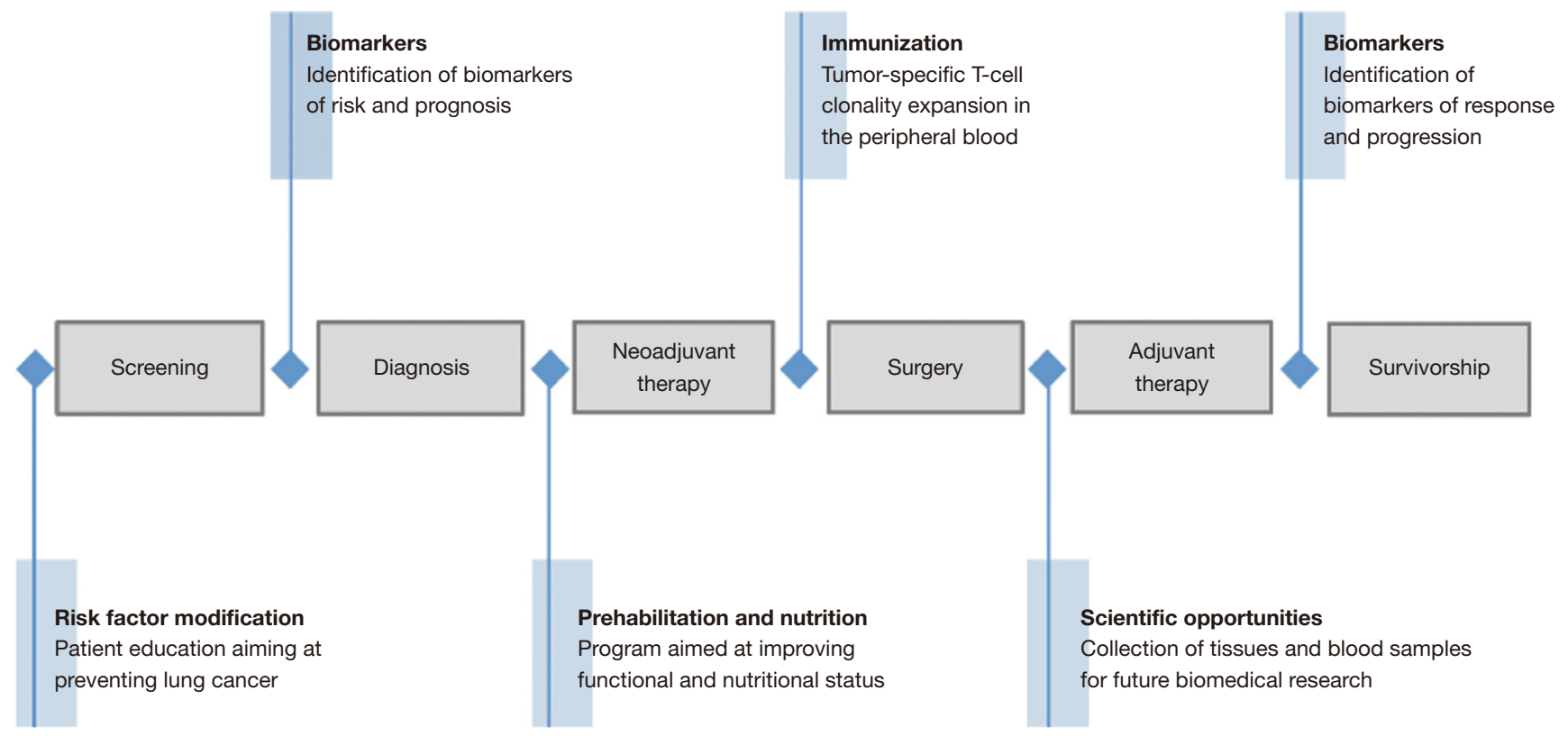

Figure 2 Process mapping of a patient with NSCLC. The patient's trajectory from screening and diagnosis to post-operative course and survivorship is inevitably influenced by the treatment modalities, whether neoadjuvant or adjuvant, offered during the process itself. Neoadjuvant therapy leads to many informative and valuable opportunities for improvement, including risk factor modification, biomarker exploration, prehabilitation, nutrition optimization and scientific discovery. NSCLC, non-small cell lung cancer.

armamentarium of treatment strategies for stage IV disease. Furthermore, the patient trajectory from screening and diagnosis to post-operative course and potential cure is inevitably influenced by numerous treatment modalities and life-style choices adopted by the patient. Neoadjuvant window therapy offers many opportunities for improvement, including optimization of patient performance status via exercise and tailored nutritional programs (116-118). Psychological stress management strategies may also carry significant benefits to facilitate the course of treatment and perhaps even impact the efficacy of treatment (119-121). Opportunities are vast for the personalization and rational selection of optimal induction therapies, paired with these allied health interventions to leverage immunophenotypic and genomic data to achieve the best chance for cure with optimal resulting quality of life (Figure 2).

\section{Neoadjuvant immunotherapy: the controversies}

Although the benefits of neoadjuvant immunotherapy are accumulating, there remain important concerns, mainly regarding the safety of this treatment modality. In fact, the optimal timing of surgery after immunotherapy remains unclear. Concerns arise amongst surgeons regarding the inflammatory consequences of immunotherapies resulting in more hilar fibrosis which may be problematic at the time of surgery, leading to more difficult dissections, longer operative times, higher conversion rates from minimal access techniques and higher complication rates. In regards to adverse effects, pre-operative concerns include delay to surgery, progression or pseudo-progression on therapy, pneumonitis and impaired healing processes (122). A recent post-hoc study described complications in $50 \%$ of patients, without any serious ones noted. Despite a high conversion rate of $54 \%$ from dissection difficulties, the median operative time remained within range (123). These results confirm those of previous smaller studies in early as well as metastatic unresectable NSCLC $(122,124)$. Some studies have suggested the feasibility of a minimally invasive approach with appropriate patient selection in resectable NSCLC $(125,126)$. In another small series of cases, it was suggested that pulmonary resection was feasible after ICI, but that mediastinal and hilar fibrosis could develop and present potential challenges to resection (127). The results of these few studies are promising, but much larger trials are needed to validate the safety and efficacy of 
immunotherapies with regards to surgical planning. Indeed, we need to determine how surgeon experience with such treatment strategies impacts outcomes and whether these approaches will be easily and safely deployed to the broader community of thoracic surgeons and oncology teams.

To better compare the efficacy and safety of various neoadjuvant immunotherapies and appropriately plan for surgery, it is essential to develop standardized guidelines to assess response and progression after treatment in these patients. Clinical evaluations are usually done by radiological imaging assessment (RECIST 1.1 for CT), which assesses the anatomical tumor burden as a surrogate for systemic therapy response (128). With PET scans, the SUV of tumors has also been used for response assessment in solid tumors, following revised imaging criteria, PERCIST (129). In fact, the SUV change after multimodal systemic treatments was described as a predictor for survival (130). Opportunities for the application of radiomic and artificial intelligence strategies to further illuminate the meaning of radiological findings on the prediction of complete response are emerging. Indeed, unsupervised non-hierarchical machine learning strategies will become essential to predicting the occurrence of MPR by integrating all available tiers of data.

Pathological response, such as MPR and pCR, have been used as primary and secondary endpoints in various studies to assess neoadjuvant chemotherapy response (51) and more recently, neoadjuvant immunotherapy response as well. In the Forde et al. study, although MPR was observed in $45 \%$ of patients, only $10 \%$ of patients showed radiological partial response to neoadjuvant nivolumab, while the majority had stable disease on CT scan (77). How such findings will impact our understanding of radiological assessments of disease progression/stability/regression in advanced disease remains to be determined. Another study evaluating CT imaging after neoadjuvant therapy reported stable disease or pseudo-progression, thought to be related to inflammation and immune-cells infiltration into the tumor during the early stages of immunotherapy treatment rather than tumor growth (123). This could suggest an important discrepancy between clinical and actual pathological responses with immunotherapy. Moreover, the concept of immune flare described by the NEOSTAR investigators is a radiological progression seen in lymph nodes after preoperative ICI requiring further pathological evaluation (85). This therefore raises the debate surrounding the need and value of invasive restaging of patients after completion of neoadjuvant therapy. Indeed, even before the era of immunotherapy, there was great variability within the thoracic surgery community regarding the need for invasive staging after completion of pre-operative therapy. Many surgeons routinely reassess mediastinal nodes either by mediastinoscopy or endobronchial ultrasound and will only operate on patients with no evidence of residual N2 lymph node disease. Our team's contention is that patients ought to be resectable at presentation prior to receiving such treatments at least as long as they are investigational in nature. As such, unless new findings appear after induction therapy such as suspicious contralateral lymph node disease or lesions suspicious for extrathoracic metastasis, the value of invasive staging is minimal. A careful analysis of largescale phase 3 studies of neoadjuvant immunotherapy will hopefully shed light on the importance of these controversial and resource intensive procedures.

As mentioned earlier, several techniques exist for pathological assessment of post-neoadjuvant treated patients. Pathologic features and criteria were first developed to assess chemotherapy response and prognosis after treatment (131). However, given the differences that exist between the mechanism of action of chemotherapy and immunotherapy, the pathological interpretation of findings present new challenges. In the setting of immunotherapy, several types of tumors were studied after anti-PD-L1 therapy. The investigators described common features of immune-related pathologic response (irPR) such as immune activation, cell death, tissue repair and regression bed features. These were consistent across primary tumors, lymph nodes and distant metastases (132). It is important to note that because the regression bed can be close to, but not necessarily part of the residual tumor at surgery, these areas would therefore need to be specifically sought out and resected for examination to comply with these criteria (133). This type of scoring system will need validation with larger studies and may present challenges for patients undergoing sublobar resection. Nevertheless, there are promising data for the creation of meaningful pathological response assessment guidelines.

Although there was no absolute correlation between pathologic response and PD-L1 status, the Forde et al. trial showed that PD-L1 might play a role in activating the antitumor T-cells and thus eliminating micrometastases that would otherwise lead to recurrence. It also highlighted the higher frequency of T-cell clones shared between the tumor environment and the peripheral blood in patients with a MPR. This finding could therefore lead to a potential marker for immune response (77). Validating this 
hypothesis, all patients who had a reduction in viable tumor of $30 \%$ or more showed clearance of circulating tumor DNA (ctDNA) from their blood prior to surgery, and patients who had detectable ctDNA and residual disease at surgery were found to have minimal T-cell expansion in their peripheral blood. Analysis of ctDNA between responders and non-responders in NSCLC treated with neoadjuvant immunotherapy could also be a potential biomarker for response and prognosis (134). In fact, studies described that between $50-95 \%$ of patients with resectable (stages I to III) lung cancers seem to have detectable ctDNA at the time of diagnosis (135-137). Others also show presence of ctDNA post-surgery in patients with resectable lung cancer (138), and a few described ctDNA as a guide for residual disease, response to treatment and risk of recurrence or metastasis $(135,137,139)$. A recent prospective study enrolled patients with locally advanced rectal cancer planned for neoadjuvant chemoradiotherapy (140). ctDNA was quantified in plasma samples pre-treatment, post-treatment and post-surgery. ctDNA was capable of stratifying patients into high or low risk of recurrence groups, and thus could potentially help in guiding adjuvant treatment (141). Therefore, more studies exploring ctDNA response assessment during neoadjuvant therapy in lung canner would be useful. Many studies have focused on the assessment of anti-PD-1 and anti-PD-L1 effect on the tumor microenvironment, which involves the elimination of suppressive tumors and the rejuvenation of exhausted T cells (142). The TMB has been an emerging area of interest in various types of cancers $(143,144)$, using whole exome sequencing and genomic profiling which could subsequently predict response to treatment. Although the Forde $e t$ al. study did not show a strong correlation between PD-L1 status and MPR, it did reveal a higher TMB with tumors achieving MPR compared to those who did not (77). There exist many biomarkers, but to date, none have been identified to be significantly reliable and predictive. Further than predicting response to treatment, a liquid biopsy could potentially predict prognosis, resistance to treatment and risk of adverse effects (145).

With the emergence of combination therapies, including the addition of radiation and/or systemic therapies to surgery for resectable patients, measures taken to evaluate adverse events in the context of systemic therapies become primordial. In fact, the unpredictable impact of these new combination therapies is a significant concern (140). ICIs increase the system's natural tumor killing response, which can lead to immune-related adverse events involving many organs such as the lung, the intestines, the skin and the endocrine system $(140,146)$. These side effects are usually benign or treatable, but can rarely lead to serious or life-threatening events, prompting rapid recognition and initiation of treatment by specialists in the field (147). In fact, the incidence of grade 3 and 4 treatment-related adverse events with ICI varies between $7 \%$ and $30 \%$, which is lower than with chemotherapy $(148,149)$, but higher with the use of combination therapies (148). Although the frequency of adverse events seem to be dependent on the type of immunotherapy, a recent metaanalysis revealed similar incidences between anti-PD-1 and anti-PD-L1 (150). The treatment of moderate to severe toxicities usually involves ICI interruption or a short course of corticosteroids (149). The most common adverse event with ICI is immune-related thyroiditis, which can be asymptomatic or can transition to hypothyroidism requiring long-term supplementation. This evolution to long-term effects also seem to be more rapid and more frequent with combination therapies (151). Given variable and unclear side effects from ICI and combination therapies, the results of ongoing larger trials will be important to adequately select patients and optimize cost-benefit.

The previously published trials discussed in this review generally included all resectable NSCLC patients, without a specific selection process or criteria, leading to preoperative systemic treatment of all patients. Moving forward, the results of ongoing large-size randomized trials will provide more information in regards to selecting patients that will benefit from these treatments. These ongoing trials will also help answer many of the remaining issues and controversies surrounding the topic. To be sure, these trials will certainly also open many new questions to be addressed in the future.

\section{Conclusions}

Although surgery as a single modality remains the standard of care for resectable and operable NSCLC patients, immunotherapy's broad successes over traditional chemotherapy in locally advanced and metastatic lung cancer has led to a shift in management for earlier stages, initiating the investigation of immunotherapy in the neoadjuvant setting aimed at better outcomes and lower recurrence rates. Despite numerous published trials with encouraging results, several questions remain unanswered. Many of these surround the details of drug regimens (including choice of molecule, number of doses and optimal combinations), need for adjuvant therapy and optimal timing of surgery. Additionally, issues concerning combination therapies, 
such as when to give (simultaneous versus sequential) and which immunotherapy to give in patients who will also receive radiation and $K R A S$ inhibitors, are also emerging. With the arrival of new therapeutic options, the criteria for response and progression assessment as well as adverse event evaluation will be essential. In fact, although MPR has a great biological efficacy for evaluating survival in resectable NSCLC, what will this mean for immunotherapy response assessment and restaging? This will be specifically important with combination therapies, such as radiation. Given the discordance between both modalities seen in some trials, will radiological and pathological assessments be sufficient to differentiate between progression versus pseudo-progression or immune flare? On the other hand, will the development of liquid biopsies, using information such as ctDNA assessments, be able to help us avoid invasive re-staging and inform us further about the utility of surgery if a pCR has occurred? At this time, there is no right answer or standardized approach established, but the ongoing phase III trials for neoadjuvant immunotherapy in NSCLC will be critical in elucidating some of the ongoing controversies and debates, as well as provide light to many unanswered questions. How will these therapies impact even earlier stages of NSCLC where systemic recurrence remains far too common? Overall, the emerging data are creating a paradigm shift in care strategies for early-stage lung cancers-this wave of optimism will bring many new discoveries and improved outcomes for our patients.

\section{Acknowledgments}

Funding: None.

\section{Footnote}

Provenance and Peer Review: This article was commissioned by the Guest Editor (Mariano Provencio) for the series "Multimodal management of locally advanced N2 nonsmall cell lung cancer" published in Translational Lung Cancer Research. The article has undergone external peer review.

Peer Review File: Available at http://dx.doi.org/10.21037/ tlcr-20-509

Conflicts of Interest: All authors have completed the ICMJE uniform disclosure form (available at http://dx.doi. org/10.21037/tlcr-20-509). The series "Multimodal management of locally advanced N2 non-small cell lung cancer" was commissioned by the editorial office without any funding or sponsorship. JDS serves on the scientific advisory board for Trans-Hit Bio Inc., is a member of clinical trial steering committees for AstraZeneca and Bristol-Myers-Squibb and has received clinical trial funding from Merck. The authors have no other conflicts of interest to declare.

Ethical Statement: The authors are accountable for all aspects of the work in ensuring that questions related to the accuracy or integrity of any part of the work are appropriately investigated and resolved.

Open Access Statement: This is an Open Access article distributed in accordance with the Creative Commons Attribution-NonCommercial-NoDerivs 4.0 International License (CC BY-NC-ND 4.0), which permits the noncommercial replication and distribution of the article with the strict proviso that no changes or edits are made and the original work is properly cited (including links to both the formal publication through the relevant DOI and the license). See: https://creativecommons.org/licenses/by-nc-nd/4.0/.

\section{References}

1. Walter JE, Heuvelmans MA, de Jong PA, et al. Occurrence and lung cancer probability of new solid nodules at incidence screening with low-dose CT: analysis of data from the randomised, controlled NELSON trial. Lancet Oncol 2016;17:907-16.

2. Postmus PE, Kerr KM, Oudkerk M, et al. Early and locally advanced non-small-cell lung cancer (NSCLC): ESMO Clinical Practice Guidelines for diagnosis, treatment and follow-up. Ann Oncol 2017;28:iv1-21.

3. National Lung Screening Trial Research Team, Aberle DR, Adams AM, et al. Reduced lung-cancer mortality with low-dose computed tomographic screening. N Engl J Med 2011;365:395-409.

4. Rosen JE, Keshava HB, Yao X, et al. The natural history of operable non-small cell lung cancer in the National Cancer Database. Ann Thorac Surg 2016;101:1850-5.

5. Papanikolaou IG, Dimitrakakis C, Zagouri F, et al. Paving the way for changing perceptions in breast surgery: a systematic literature review focused on oncological and aesthetic outcomes of oncoplastic surgery for breast cancer. Breast Cancer 2019;26:416-27.

6. Lee J, Jung JH, Kim WW, et al. Comparison of 5-year 
oncological outcomes of breast cancer based on surgery type. ANZ J Surg 2018;88:E395-9.

7. Uramoto H, Tanaka F. Prediction of recurrence after complete resection in patients with NSCLC. Anticancer Res 2012;32:3953-60.

8. Billè A, Ahmad U, Woo KM, et al. Detection of recurrence patterns after wedge resection for early stage lung cancer: rationale for radiologic follow-up. Ann Thorac Surg 2016;102:1067-73.

9. Isaka M, Kojima H, Takahashi S, et al. Risk factors for local recurrence after lobectomy and lymph node dissection in patients with non-small cell lung cancer: Implications for adjuvant therapy. Lung Cancer 2018;115:28-33.

10. Uramoto H, Tanaka F. Recurrence after surgery in patients with NSCLC. Transl Lung Cancer Res 2014;3:242-9.

11. Napolitano S, Brancaccio G, Argenziano G, et al. It is finally time for adjuvant therapy in melanoma. Cancer Treat Rev 2018;69:101-11.

12. Pondé NF, Zardavas D, Piccart M. Progress in adjuvant systemic therapy for breast cancer. Nat Rev Clin Oncol 2019;16:27-44.

13. Schiller JH, Harrington D, Belani CP, et al. Comparison of four chemotherapy regimens for advanced non-smallcell lung cancer. N Engl J Med 2002;346:92-8.

14. Chemotherapy in non-small cell lung cancer: a metaanalysis using updated data on individual patients from 52 randomised clinical trials. Non-small Cell Lung Cancer Collaborative Group. BMJ 1995;311:899-909.

15. NSCLC Meta-analysis Collaborative Group. Preoperative chemotherapy for non-small-cell lung cancer: a systematic review and meta-analysis of individual participant data. Lancet 2014;383:1561-71.

16. Burdett S, Pignon JP, Tierney J, et al. Adjuvant chemotherapy for resected early-stage non-small cell lung cancer. Cochrane Database Syst Rev 2015;(3):CD011430.

17. NSCLC Meta-analysis Collaborative Group; Arriagada R, Auperin A, et al. Adjuvant chemotherapy, with or without postoperative radiotherapy, in operable non-small-cell lung cancer: two meta-analyses of individual patient data. Lancet 2010;375:1267-77.

18. Albain KS, Swann RS, Rusch VW, et al. Radiotherapy plus chemotherapy with or without surgical resection for stage III non-small-cell lung cancer: a phase III randomised controlled trial. Lancet 2009;374:379-86.

19. Spicer JD, Shewale JB, Nelson DB, et al. Multimodality therapy for N2 non-small cell lung cancer: an evolving paradigm. Ann Thorac Surg 2019;107:277-84.

20. Xu YP, Li B, Xu XL, et al. Is There a survival benefit in patients with stage IIIA (N2) non-small cell lung cancer receiving neoadjuvant chemotherapy and/or radiotherapy prior to surgical resection: a systematic review and metaanalysis. Medicine (Baltimore) 2015;94:e879.

21. Chen Y, Peng X, Zhou Y, et al. Comparing the benefits of chemoradiotherapy and chemotherapy for resectable stage III A/N2 non-small cell lung cancer: a meta-analysis. World J Surg Oncol 2018;16:8.

22. Sher DJ, Fidler MJ, Liptay MJ, et al. Comparative effectiveness of neoadjuvant chemoradiotherapy versus chemotherapy alone followed by surgery for patients with stage IIIA non-small cell lung cancer. Lung Cancer 2015;88:267-74.

23. Brandt WS, Yan W, Zhou J, et al. Outcomes after neoadjuvant or adjuvant chemotherapy for cT2-4N0-1 non-small cell lung cancer: a propensity-matched analysis. J Thorac Cardiovasc Surg 2019;157:743-53.e3.

24. O'Donnell JS, Hoefsmit EP, Smyth MJ, et al. The promise of neoadjuvant immunotherapy and surgery for cancer treatment. Clin Cancer Res 2019;25:5743-51.

25. Sharon E, Streicher H, Goncalves P, et al. Immune checkpoint inhibitors in clinical trials. Chin J Cancer 2014;33:434-44.

26. Brahmer J, Reckamp KL, Baas $P$, et al. Nivolumab versus docetaxel in advanced squamous-cell non-small-cell lung cancer. N Engl J Med 2015;373:123-35.

27. Borghaei H, Paz-Ares L, Horn L, et al. Nivolumab versus docetaxel in advanced nonsquamous non-small-cell lung cancer. N Engl J Med 2015;373:1627-39.

28. Herbst RS, Baas P, Kim DW, et al. Pembrolizumab versus docetaxel for previously treated, PD-L1-positive, advanced non-small-cell lung cancer (KEYNOTE-010): a randomised controlled trial. Lancet 2016;387:1540-50.

29. Fehrenbacher L, Spira A, Ballinger M, et al. Atezolizumab versus docetaxel for patients with previously treated non-small-cell lung cancer (POPLAR): a multicentre, open-label, phase 2 randomised controlled trial. Lancet 2016;387:1837-46.

30. Rittmeyer A, Barlesi F, Waterkamp D, et al. Atezolizumab versus docetaxel in patients with previously treated non-small-cell lung cancer (OAK): a phase 3, openlabel, multicentre randomised controlled trial. Lancet 2017;389:255-65.

31. Topalian SL, Hodi FS, Brahmer JR, et al. Safety, activity, and immune correlates of anti-PD-1 antibody in cancer. $\mathrm{N}$ Engl J Med 2012;366:2443-54.

32. Reck M, Rodriguez-Abreu D, Robinson AG, et al. Pembrolizumab versus chemotherapy for PD-L1- 
positive non-small-cell lung cancer. N Engl J Med 2016;375:1823-33.

33. Reck M, Rodriguez-Abreu D, Robinson AG, et al. Updated analysis of KEYNOTE-024: pembrolizumab versus platinum-based chemotherapy for advanced nonsmall-cell lung cancer with PD-L1 tumor proportion score of 50\% or greater. J Clin Oncol 2019;37:537-46.

34. Langer CJ, Gadgeel SM, Borghaei H, et al. Carboplatin and pemetrexed with or without pembrolizumab for advanced, non-squamous non-small-cell lung cancer: a randomised, phase 2 cohort of the open-label KEYNOTE-021 study. Lancet Oncol 2016;17:1497-508.

35. Gandhi L, Rodriguez-Abreu D, Gadgeel S, et al. Pembrolizumab plus chemotherapy in metastatic nonsmall-cell lung cancer. N Engl J Med 2018;378:2078-92.

36. Paz-Ares L, Luft A, Vicente D, et al. Pembrolizumab plus chemotherapy for squamous non-small-cell lung cancer. $\mathrm{N}$ Engl J Med 2018;379:2040-51.

37. Socinski MA, Jotte RM, Cappuzzo F, et al. Atezolizumab for first-line treatment of metastatic nonsquamous NSCLC. N Engl J Med 2018;378:2288-301.

38. Jotte RM, Cappuzzo F, Vynnychenko I, et al. IMpower131: Primary PFS and safety analysis of a randomized phase III study of atezolizumab + carboplatin + paclitaxel or nab-paclitaxel vs carboplatin + nab-paclitaxel as $1 \mathrm{~L}$ therapy in advanced squamous NSCLC. J Clin Oncol 2018;36:LBA9000.

39. Lee CK, Man J, Lord S, et al. Checkpoint inhibitors in metastatic EGFR-mutated non-small cell lung cancer-a meta-analysis. J Thorac Oncol 2017;12:403-7.

40. Hellmann MD, Ciuleanu TE, Pluzanski A, et al. Nivolumab plus ipilimumab in lung cancer with a high tumor mutational burden. N Engl J Med 2018;378:2093-104.

41. Gettinger S, Horn L, Jackman D, et al. Five-year followup of nivolumab in previously treated advanced non-smallcell lung cancer: results from the CA209-003 study. J Clin Oncol 2018;36:1675-84.

42. Rosner S, Reuss JE, Forde PM. PD-1 blockade in earlystage lung cancer. Annu Rev Med 2019;70:425-35.

43. Aupérin A, Le Péchoux C, Pignon JP, et al. Concomitant radio-chemotherapy based on platin compounds in patients with locally advanced non-small cell lung cancer (NSCLC): a meta-analysis of individual data from 1764 patients. Ann Oncol 2006;17:473-83.

44. Melosky B, Juergens R, McLeod D, et al. Immune checkpoint-inhibitors and chemoradiation in stage III unresectable non-small cell lung cancer. Lung Cancer
2019;134:259-67.

45. Antonia SJ, Villegas A, Daniel D, et al. Durvalumab after chemoradiotherapy in stage III non-small-cell lung cancer. N Engl J Med 2017;377:1919-29.

46. Antonia SJ, Villegas A, Daniel D, et al. Overall survival with durvalumab after chemoradiotherapy in stage III NSCLC. N Engl J Med 2018;379:2342-50.

47. Gray JE, Villegas A, Daniel D, et al. Three-year overall survival with durvalumab after chemoradiotherapy in stage III NSCLC-update from PACIFIC. J Thorac Oncol 2020;15:288-93.

48. Chaft JE, Dahlberg SE, Khullar OV, et al. EA5142 adjuvant nivolumab in resected lung cancers (ANVIL). J Clin Oncol 2018;36:abstr TPS8581.

49. Wakelee HA, Altorki NK, Vallieres E, et al. A phase III trial to compare atezolizumab (atezo) vs best supportive care (BSC) following adjuvant chemotherapy in patients (pts) with completely resected NSCLC: IMpower010. J Clin Oncol 2017;35:abstr TPS8576.

50. O'Brien MER, Hasan B, Dafni U, et al. EORTC-ETOP randomized, phase 3 trial with anti-PD-1 monoclonal antibody pembrolizumab versus placebo for patients with early stage non-small cell lung cancer (NSCLC) after resection and standard adjuvant chemotherapy: PEARLS (NCT02504372). J Clin Oncol 2016;34:abstr TPS8571.

51. Hellmann MD, Chaft JE, William WN, et al. Pathological response after neoadjuvant chemotherapy in resectable non-small-cell lung cancers: proposal for the use of major pathological response as a surrogate endpoint. Lancet Oncol 2014;15:e42-50.

52. Durm GA, Althouse SK, Sadiq AA, et al. Phase II trial of concurrent chemoradiation with consolidation pembrolizumab in patients with unresectable stage III nonsmall cell lung cancer: Hoosier Cancer Research Network LUN 14-179. J Clin Oncol 2018;36:abstr 8500.

53. Peters S, Ruysscher DD, Dafni U, et al. Safety evaluation of nivolumab added concurrently to radiotherapy in a standard first line chemo-RT regimen in unresectable locally advanced NSCLC: the ETOP NICOLAS phase II trial. J Clin Oncol 2018;36:abstr 8510.

54. Lin SH, Lin Y, Price J, et al. DETERRED: PD-L1 blockade to evaluate the safety of lung cancer therapy using carboplatin, paclitaxel, and radiation combined with MPDL3280A (atezolizumab). J Clin Oncol 2017;35:abstr 3064.

55. Lin S, Lin X, Clay D, et al. OA01.06 DETERRED: Phase II trial combining atezolizumab concurrently with chemoradiation therapy in locally advanced non-small cell 
lung cancer. J Thorac Oncol 2018;13:S320-1.

56. Ridker PM, Everett BM, Thuren T, et al. Antiinflammatory Therapy with Canakinumab for Atherosclerotic Disease. N Engl J Med 2017;377:1119-31.

57. Aday AW, Ridker PM. Antiinflammatory therapy in clinical care: the CANTOS trial and beyond. Front Cardiovasc Med 2018;5:62.

58. Paz-Ares LG, Garon EB, Ardizzoni A, et al. The CANOPY program: Canakinumab in patients (pts) with non-small cell lung cancer (NSCLC). J Clin Oncol 2019;37:abstr TPS9124.

59. Garon EB, Ardizzoni A, Barlesi F, et al. CANOPY-A: A phase III study of canakinumab as adjuvant therapy in patients with surgically resected non-small cell lung cancer (NSCLC). J Clin Oncol 2019;37:abstr TPS8570.

60. Felip E, Castro G, Greystoke A, et al. P2.0117 CANOPY-1: Phase 3 study of canakinumab/ placebo+pembrolizumab+platinum-chemotherapy in untreated stage IIIB-IV NSCLC pts. J Thorac Oncol 2019;14:S645.

61. Papadimitrakopoulou VA, Goto Y, Lim DWT, et al. PD01.06 CANOPY-2: Phase 3 study of canakinumab plus docetaxel as second/third line therapy in locally advanced/ metastatic NSCLC. J Thorac Oncol 2019;14:S1136.

62. Schmid P, Park YH, Muñoz-Couselo E, et al. Pembrolizumab (pembro) + chemotherapy (chemo) as neoadjuvant treatment for triple negative breast cancer (TNBC): preliminary results from KEYNOTE-173. J Clin Oncol 2017;35:abstr 556.

63. Franklin C, Livingstone E, Roesch A, et al. Immunotherapy in melanoma: recent advances and future directions. Eur J Surg Oncol 2017;43:604-11.

64. Blank CU, Rozeman EA, Fanchi LF, et al. Neoadjuvant versus adjuvant ipilimumab plus nivolumab in macroscopic stage III melanoma. Nat Med 2018;24:1655-61.

65. Rozeman EA, Sikorska K, van de Wiel BA, et al. 30 months relapse-free survival, overall survival, and longterm toxicity update of (neo)adjuvant ipilimumab (ipi) + nivolumab (nivo) in macroscopic stage III melanoma (OPACIN trial). Ann Oncol 2018;29:LBA3.

66. Amaria RN, Reddy SM, Tawbi HAH, et al. Neoadjuvant (neo) immune checkpoint blockade (ICB) in patients (Pts) with high-risk resectable metastatic melanoma (MM). J Clin Oncol 2018;36:abstr 9510.

67. Amaria RN, Reddy SM, Tawbi HA, et al. Neoadjuvant immune checkpoint blockade in high-risk resectable melanoma. Nat Med 2018;24:1649-54.

68. Huang AC, Orlowski RJ, Xu X, et al. A single dose of neoadjuvant PD-1 blockade predicts clinical outcomes in resectable melanoma. Nat Med 2019;25:454-61.

69. Necchi A, Raggi D, Gallina A, et al. Updated results of PURE-01 with preliminary activity of neoadjuvant pembrolizumab in patients with muscle-invasive bladder carcinoma with variant histologies. Eur Urol 2020;77:439-46.

70. Sun Y, Liao M, He L, et al. Comparison of breastconserving surgery with mastectomy in locally advanced breast cancer after good response to neoadjuvant chemotherapy: a PRISMA-compliant systematic review and meta-analysis. Medicine (Baltimore) 2017;96:e8367.

71. Teshome M, Kuerer HM. Breast conserving surgery and locoregional control after neoadjuvant chemotherapy. Eur J Surg Oncol 2017;43:865-74.

72. Roth JA, Fossella F, Komaki R, et al. A randomized trial comparing perioperative chemotherapy and surgery with surgery alone in resectable stage IIIA non-small-cell lung cancer. J Natl Cancer Inst 1994;86:673-80.

73. Roth JA, Atkinson EN, Fossella F, et al. Long-term followup of patients enrolled in a randomized trial comparing perioperative chemotherapy and surgery with surgery alone in resectable stage IIIA non-small-cell lung cancer. Lung Cancer 1998;21:1-6.

74. Rosell R, Gomez-Codina J, Camps C, et al. A randomized trial comparing preoperative chemotherapy plus surgery with surgery alone in patients with non-small-cell lung cancer. N Engl J Med 1994;330:153-8.

75. National Collaborating Centre for Cancer. Treatment with curative intent for NSCLC. In: The Diagnosis and Treatment of Lung Cancer (Update). Cardiff: National Collaborating Centre for Cancer (UK), 2011.

76. Herbst RS, Tsuboi M, John T, et al. Osimertinib as adjuvant therapy in patients (pts) with stage IB-IIIA EGFR mutation positive (EGFRm) NSCLC after complete tumor resection: ADAURA. J Clin Oncol 2020;38:LBA5.

77. Forde PM, Chaft JE, Smith KN, et al. Neoadjuvant PD-1 blockade in resectable lung cancer. $\mathrm{N}$ Engl J Med 2018;378:1976-86.

78. Pisters KM, Kris MG, Gralla RJ, et al. Pathologic complete response in advanced non-small-cell lung cancer following preoperative chemotherapy: implications for the design of future non-small-cell lung cancer combined modality trials. J Clin Oncol 1993;11:1757-62.

79. Scagliotti GV, Parikh P, von Pawel J, et al. Phase III study comparing cisplatin plus gemcitabine with cisplatin plus pemetrexed in chemotherapy-naive patients with advanced-stage non-small-cell lung cancer. J Clin Oncol 
2008;26:3543-51.

80. Felip E, Rosell R, Maestre JA, et al. Preoperative chemotherapy plus surgery versus surgery plus adjuvant chemotherapy versus surgery alone in early-stage nonsmall-cell lung cancer. J Clin Oncol 2010;28:3138-45.

81. Nagai K, Tsuchiya R, Mori T, et al. A randomized trial comparing induction chemotherapy followed by surgery with surgery alone for patients with stage IIIA N2 nonsmall cell lung cancer (JCOG 9209). J Thorac Cardiovasc Surg 2003;125:254-60.

82. Martin J, Ginsberg RJ, Venkatraman ES, et al. Long-term results of combined-modality therapy in resectable nonsmall-cell lung cancer. J Clin Oncol 2002;20:1989-95.

83. Betticher DC, Hsu Schmitz SF, Totsch M, et al. Mediastinal lymph node clearance after docetaxel-cisplatin neoadjuvant chemotherapy is prognostic of survival in patients with stage IIIA pN2 non-small-cell lung cancer: a multicenter phase II trial. J Clin Oncol 2003;21:1752-9.

84. Chaft JE, Rusch V, Ginsberg MS, et al. Phase II trial of neoadjuvant bevacizumab plus chemotherapy and adjuvant bevacizumab in patients with resectable nonsquamous non-small-cell lung cancers. J Thorac Oncol 2013;8:1084-90.

85. Cascone T, William WN, Weissferdt A, et al. Neoadjuvant nivolumab $(\mathrm{N})$ or nivolumab plus ipilimumab (NI) for resectable non-small cell lung cancer (NSCLC): clinical and correlative results from the NEOSTAR study. J Clin Oncol 2019;37:abstr 8504.

86. Rusch VW, Chaft JE, Johnson B, et al. Neoadjuvant atezolizumab in resectable non-small cell lung cancer (NSCLC): initial results from a multicenter study (LCMC3). J Clin Oncol 2018;36:abstr 8541.

87. Kwiatkowski DJ, Rusch VW, Chaft JE, et al. Neoadjuvant atezolizumab in resectable non-small cell lung cancer (NSCLC): interim analysis and biomarker data from a multicenter study (LCMC3). J Clin Oncol 2019;37:abstr 8503 .

88. Li N, Ying J, Tao X, et al. Efficacy and safety of neoadjuvant PD-1 blockade with sintilimab in resectable squamous non-small cell lung cancer (sqNSCLC). J Clin Oncol 2019;37:abstr 8531.

89. Provencio-Pulla M, Nadal-Alforja E, Cobo M, et al. Neoadjuvant chemo/immunotherapy for the treatment of stages IIIA resectable non-small cell lung cancer (NSCLC): a phase II multicenter exploratory study-NADIM studySLCG. J Clin Oncol 2018;36:abstr 8521.

90. Provencio-Pulla M, Nadal-Alforja E, Cobo M, et al. Neoadjuvant chemo-immunotherapy for the treatment of stage IIIA resectable non-small-cell lung cancer (NSCLC): a phase II multicenter exploratory study-Final data of patients who underwent surgical assessment. J Clin Oncol 2019;37:abstr 8509.

91. Shu CA, Grigg C, Chiuzan C, et al. Neoadjuvant atezolizumab + chemotherapy in resectable non-small cell lung cancer (NSCLC). J Clin Oncol 2018;36:abstr 8532.

92. Takamori S, Toyokawa G, Takada K, et al. Combination therapy of radiotherapy and anti-PD-1/PD-L1 treatment in non-small-cell lung cancer: a mini-review. Clin Lung Cancer 2018;19:12-6.

93. Deng L, Liang H, Burnette B, et al. Irradiation and antiPD-L1 treatment synergistically promote antitumor immunity in mice. J Clin Invest 2014;124:687-95.

94. Shaverdian N, Lisberg AE, Bornazyan K, et al. Previous radiotherapy and the clinical activity and toxicity of pembrolizumab in the treatment of non-small-cell lung cancer: a secondary analysis of the KEYNOTE-001 phase 1 trial. Lancet Oncol 2017;18:895-903.

95. Altorki N, Borczuk A, Saxena A, et al. P2.04-92 Neoadjuvant durvalumab with or without sub-ablative stereotactic radiotherapy (SBRT) in patients with resectable NSCLC (NCT02904954). J Thorac Oncol 2019;14:S746.

96. Heigener DF, Reck M. Immune checkpoint inhibition in non-metastatic non-small cell lung cancer: chance for cure? Drugs 2019;79:1937-45.

97. Eichhorn F, Klotz LV, Bischoff H, et al. Neoadjuvant antiprogrammed death-1 immunotherapy by pembrolizumab in resectable nodal positive stage II/IIIa non-small-cell lung cancer (NSCLC): the NEOMUN trial. BMC Cancer 2019;19:413.

98. Mignard X, Antoine M, Moro-Sibilot D, et al. IoNESCO trial: Immune neoajuvant therapy in early stage non-small cell lung cancer. Rev Mal Respir 2018;35:983-8.

99. Campelo RG, Forde P, Weder W, et al. P2.04-28 NeoCOAST: Neoadjuvant durvalumab alone or with novel agents for resectable, early-stage (I-IIIA) non-small cell lung cancer. J Thorac Oncol 2019;14:S719.

100. Forde PM, Chaft JE, Felip E, et al. Checkmate 816: A phase 3, randomized, open-label trial of nivolumab plus ipilimumab vs platinum-doublet chemotherapy as neoadjuvant treatment for early-stage NSCLC. J Clin Oncol 2017;35:abstr TPS8577.

101. Felip E, Brahmer J, Broderick S, et al. P2.16-03 CheckMate 816: A phase 3 trial of neoadjuvant nivolumab plus ipilimumab or chemotherapy vs chemotherapy in early-stage NSCLC. J Thorac Oncol 2018;13:S831-2. 
102. Rizvi N, Gandara D, Solomon B, et al. P2.17-27 IMpower030: Phase III study evaluating neoadjuvant treatment of resectable stage II-IIIB NSCLC with atezolizumab + chemotherapy. J Thorac Oncol 2018;13:S863.

103. Rothschild S, Zippelius A, Savic S, et al. SAKK 16/14: Anti-PD-L1 antibody durvalumab (MEDI4736) in addition to neoadjuvant chemotherapy in patients with stage IIIA(N2) non-small cell lung cancer (NSCLC)A multicenter single-arm phase II trial. J Clin Oncol 2018;36:abstr TPS8584.

104. Heymach J, Taube J, Mitsudomi T, et al. P1.18-02 The AEGEAN phase 3 trial of neoadjuvant/adjuvant durvalumab in patients with resectable stage II/III NSCLC. J Thorac Oncol 2019;14:S625-6.

105.Hellmann MD, Rizvi NA, Goldman JW, et al. Nivolumab plus ipilimumab as first-line treatment for advanced nonsmall-cell lung cancer (CheckMate 012): results of an open-label, phase 1, multicohort study. Lancet Oncol 2017;18:31-41.

106.Fernando HC, Yang J, Ferraro GL, et al. Randomized, double-blind phase 3 study evaluating neoadjuvant platinum-based chemotherapy with perioperative pembrolizumab or placebo in resectable stage IIB or IIIA NSCLC: KEYNOTE-671. J Clin Oncol 2018;36:abstr TPS8583.

107.Liu J, Blake SJ, Yong MC, et al. Improved efficacy of neoadjuvant compared to adjuvant immunotherapy to eradicate metastatic disease. Cancer Discov 2016;6:1382-99.

108. Brooks J, Fleischmann-Mundt B, Woller N, et al. Perioperative, spatiotemporally coordinated activation of $\mathrm{T}$ and NK cells prevents recurrence of pancreatic cancer. Cancer Res 2018;78:475-88.

109. Topalian SL, Taube JM, Pardoll DM. Neoadjuvant checkpoint blockade for cancer immunotherapy. Science 2020;367: eaax0182.

110. Wei SC, Duffy CR, Allison JP. Fundamental mechanisms of immune checkpoint blockade therapy. Cancer Discov 2018;8:1069-86.

111. Melero I, Berraondo P, Rodriguez-Ruiz ME, et al. Making the most of cancer surgery with neoadjuvant immunotherapy. Cancer Discov 2016;6:1312-4.

112. Markowitz GJ, Havel LS, Crowley MJ, et al. Immune reprogramming via $\mathrm{PD}-1$ inhibition enhances early-stage lung cancer survival. JCI Insight 2018;3:e96836.

113. Anagnostou V, Smith KN, Forde PM, et al. Evolution of neoantigen landscape during immune checkpoint blockade in non-small cell lung cancer. Cancer Discov 2017;7:264-76.

114.Zhang J, Ji Z, Caushi JX, et al. Compartmental analysis of T-cell clonal dynamics as a function of pathologic response to neoadjuvant PD-1 blockade in resectable non-small cell lung cancer. Clin Cancer Res 2020;26:1327-37.

115.Smith KN, Llosa NJ, Cottrell TR, et al. Persistent mutant oncogene specific $\mathrm{T}$ cells in two patients benefitting from anti-PD-1. J Immunother Cancer 2019;7:40.

116. Santa Mina D, Scheede-Bergdahl C, Gillis C, et al. Optimization of surgical outcomes with prehabilitation. Appl Physiol Nutr Metab 2015;40:966-9.

117. Gillis C, Carli F. Promoting perioperative metabolic and nutritional care. Anesthesiology 2015;123:1455-72.

118. Minnella EM, Carli F. Prehabilitation and functional recovery for colorectal cancer patients. Eur J Surg Oncol 2018;44:919-26.

119. Carli F, Gillis C, Scheede-Bergdahl C. Promoting a culture of prehabilitation for the surgical cancer patient. Acta Oncol 2017;56:128-33.

120.Scheede-Bergdahl C, Minnella EM, Carli F. Multi-modal prehabilitation: addressing the why, when, what, how, who and where next? Anaesthesia 2019;74 Suppl 1:20-6.

121. Barrett-Bernstein M, Carli F, Gamsa A, et al. Depression and functional status in colorectal cancer patients awaiting surgery: impact of a multimodal prehabilitation program. Health Psychol 2019;38:900-9.

122. Bott MJ, Cools-Lartigue J, Tan KS, et al. Safety and feasibility of lung resection after immunotherapy for metastatic or unresectable tumors. Ann Thorac Surg 2018;106:178-83.

123. Bott MJ, Yang SC, Park BJ, et al. Initial results of pulmonary resection after neoadjuvant nivolumab in patients with resectable non-small cell lung cancer. J Thorac Cardiovasc Surg 2019;158:269-76.

124. Yang CJ, McSherry F, Mayne NR, et al. Surgical outcomes after neoadjuvant chemotherapy and ipilimumab for nonsmall cell lung cancer. Ann Thorac Surg 2018;105:924-9.

125. Yang CF, Adil SM, Anderson KL, et al. Impact of patient selection and treatment strategies on outcomes after lobectomy for biopsy-proven stage IIIA pN2 non-small cell lung cancer. Eur J Cardiothorac Surg 2016;49:1607-13.

126. Kamel MK, Nasar A, Stiles BM, et al. Video-assisted thoracoscopic lobectomy is the preferred approach following induction chemotherapy. J Laparoendosc Adv Surg Tech A 2017;27:495-500.

127. Chaft JE, Hellmann MD, Velez MJ, et al. Initial experience with lung cancer resection after treatment with T-cell 
checkpoint inhibitors. Ann Thorac Surg 2017;104:e217-8.

128. Eisenhauer EA, Therasse P, Bogaerts J, et al. New response evaluation criteria in solid tumours: revised RECIST guideline (version 1.1). Eur J Cancer 2009;45:228-47.

129. Wahl RL, Jacene H, Kasamon Y, et al. From RECIST to PERCIST: evolving considerations for PET response criteria in solid tumors. J Nucl Med 2009;50 Suppl 1:122S-50S.

130.Pöttgen C, Gauler T, Bellendorf A, et al. Standardized uptake decrease on $[18 \mathrm{~F}]$-fluorodeoxyglucose positron emission tomography after neoadjuvant chemotherapy is a prognostic classifier for long-term outcome after multimodality treatment: secondary analysis of a randomized trial for resectable stage IIIA/B non-small-cell lung cancer. J Clin Oncol 2016;34:2526-33.

131. Pataer A, Kalhor N, Correa AM, et al. Histopathologic response criteria predict survival of patients with resected lung cancer after neoadjuvant chemotherapy. J Thorac Oncol 2012;7:825-32.

132. Stein JE, Lipson EJ, Cottrell TR, et al. Pan-tumor pathologic scoring of response to PD-(L)1 blockade. Clin Cancer Res 2020;26:545-51.

133. Cottrell TR, Thompson ED, Forde PM, et al. Pathologic features of response to neoadjuvant anti-PD-1 in resected non-small-cell lung carcinoma: a proposal for quantitative immune-related pathologic response criteria (irPRC). Ann Oncol 2018;29:1853-60.

134. Reuss JE, Smith KN, Anagnostou V, et al. Neoadjuvant nivolumab in resectable non-small cell lung cancer: extended follow-up and molecular markers of response. J Clin Oncol 2019;37:abstr 8524.

135. Chaudhuri AA, Chabon JJ, Lovejoy AF, et al. Early detection of molecular residual disease in localized lung cancer by circulating tumor DNA profiling. Cancer Discov 2017;7:1394-403.

136. Newman AM, Bratman SV, To J, et al. An ultrasensitive method for quantitating circulating tumor DNA with broad patient coverage. Nat Med 2014;20:548-54.

137.Abbosh C, Birkbak NJ, Wilson GA, et al. Phylogenetic ctDNA analysis depicts early-stage lung cancer evolution. Nature 2017;545:446-51.

138. Solinas C, Gombos A, Latifyan S, et al. Targeting immune checkpoints in breast cancer: an update of early results. ESMO Open 2017;2:e000255.

139. Jamal-Hanjani M, Wilson GA, McGranahan N, et al. Tracking the evolution of non-small-cell lung cancer. $\mathrm{N}$ Engl J Med 2017;376:2109-21.
140.Suresh K, Naidoo J, Lin CT, et al. Immune checkpoint immunotherapy for non-small cell lung cancer: benefits and pulmonary toxicities. Chest 2018;154:1416-23.

141. Tie J, Cohen JD, Wang Y, et al. Serial circulating tumour DNA analysis during multimodality treatment of locally advanced rectal cancer: a prospective biomarker study. Gut 2019;68:663-71.

142. Chen Q, Li T, Yue W. Drug response to PD-1/PDL1 blockade: based on biomarkers. Onco Targets Ther 2018;11:4673-83.

143. Chalmers ZR, Connelly CF, Fabrizio D, et al. Analysis of 100,000 human cancer genomes reveals the landscape of tumor mutational burden. Genome Med 2017;9:34.

144. Khagi Y, Goodman AM, Daniels GA, et al. Hypermutated circulating tumor DNA: correlation with response to checkpoint inhibitor-based immunotherapy. Clin Cancer Res 2017;23:5729-36.

145. Cai LL, Wang J. Liquid biopsy for lung cancer immunotherapy. Oncol Lett 2019;17:4751-60.

146. Michot JM, Bigenwald C, Champiat S, et al. Immunerelated adverse events with immune checkpoint blockade: a comprehensive review. Eur J Cancer 2016;54:139-48.

147.Puzanov I, Diab A, Abdallah K, et al. Managing toxicities associated with immune checkpoint inhibitors: consensus recommendations from the Society for Immunotherapy of Cancer (SITC) Toxicity Management Working Group. J Immunother Cancer 2017;5:95.

148.Xia L, Liu Y, Wang Y. PD-1/PD-L1 blockade therapy in advanced non-small-cell lung cancer: current status and future directions. Oncologist 2019;24:S31-41.

149. Costa R, Carneiro BA, Agulnik M, et al. Toxicity profile of approved anti-PD-1 monoclonal antibodies in solid tumors: a systematic review and meta-analysis of randomized clinical trials. Oncotarget 2017;8:8910-20.

150.Pillai RN, Behera M, Owonikoko TK, et al. Comparison of the toxicity profile of PD-1 versus PD-L1 inhibitors in non-small cell lung cancer: a systematic analysis of the literature. Cancer 2018;124:271-7.

151.Iyer PC, Cabanillas ME, Waguespack SG, et al. Immunerelated thyroiditis with immune checkpoint inhibitors. Thyroid 2018;28:1243-51.

Cite this article as: Huynh C, Walsh LA, Spicer JD. Surgery after neoadjuvant immunotherapy in patients with resectable non-small cell lung cancer. Transl Lung Cancer Res 2021;10(1):563-580. doi: 10.21037/tlcr-20-509 